\title{
The Current Situation of Tibetan Earthenware Artistic Design
}

\author{
Li Cai Rang La Mao ${ }^{1, a}$
}

Jingdezhen Ceramic Institute, Jingdezhen, Jiangxi, 333000

\section{Keywords: Earthenware Artistic, Tibetan Development}

\begin{abstract}
Tibetan areas of Tibetan generations to low-temperature firing of black pottery products as daily necessities, as a national handicraft pottery technology from generation to generation, has nearly a thousand years of history. As the times change, Khamtu pottery production skills gradually decline. At present, only a small number of canyons and the main inconvenience of farming in the Tibetan settlements, as well as individual potters in the continuation of the original pottery of ancient art.
\end{abstract}

\section{Introduction}

Like other types of pottery, the Tibetan pottery emerged from its origins, evolved, and finally mature, and was not isolated, but as a system of existence, and with its natural geographical environment and social humanities The environment has a direct connection. The local and national pottery form and the pottery culture show great differences between regional and nationalities. Apart from the influence of physical and economic conditions, the more important factor is that it is the product of different cultures. "Culture, in a broad sense, can include all the way of life and the things that are created by these lifestyles, as well as the psychology and behavior that are based on these ways, which contain parts of the object, The part of the heart. "This means that the culture is the most superficial thing, that is, the material culture of human creation; in the middle of the culture is the combination of mind and object, this part can be sensory, understanding experience, can direct guidance The deep is the heart, that is equivalent to the human spirit and culture, it directly affects the development of the middle layer, although far away from the object, but it is the ultimate source of the final decision. Tibetan soil pottery as a material carrier of culture, or more accurately that is a material culture in the form of existence in front of us, to varying degrees reflect the Diqing Tibetan ethnic unique cultural and psychological structure, it is these Decided to reach a certain form of Tibetan soil Earthenware method, style and technology and other aspects of the middle of things, and finally to a wide range of specific soil Earthenware form, that is, the surface culture, as the entity appears in front of people. Therefore, the art form of Tibetan pottery is a complex problem, it is impossible to carry out a single explanation, it shows that the interaction between the various factors of the results. Tibetan soil is not only a simple framework, it is composed of a series of complex purpose of the composition of the system, with intuitive vocabulary directly reflect the concept of image and lifestyle. The study of the Tibetan pottery can not only stay in the study of the superficial phenomenon, with only one of the two views and methods, not enough to fully understand the rich connotations contained in the Tibetan pottery. Therefore, to study the deep connotation of the artistic characteristics of earthenware, it is necessary to contact with its cultural core, and only to put the Tibetan soil in the environment that makes it develop and develop in order to explore the more profound and specific.

\section{The Distribution of Pottery}

From the geographical location and living habits of Tibetan areas, the Tibetan soil and Earthenwareism are mostly distributed in the Tibetan areas where the alpine canyons are located, including the Ganzi Tibetan Autonomous Prefecture, Aba Tibetan and Qiang Autonomous Prefecture and Liangshan Yi Autonomous Prefecture. Most of the Tibetan people live in alpine valleys. Earthenware raw materials mining is very difficult, many are in a very dangerous halfway up the 
mountain. Tibetan soil pottery is a raw material containing stone and soil of a clay, the color was gray, yellow, red, ocher, brown and so on, the fire resistance at about $1000{ }^{\circ} \mathrm{C}$, plasticity and viscosity better. Collected raw materials with a wooden hammer knocked into a small block drying, plateau sunshine strong, generally 1-2 days to sun through. And then use the mallet in the stone Chung or stone groove beat into a powder, after several sieving, and finally get the raw material fine flour. Use only when the water and repeatedly rub evenly. Some areas summed up the experience, in order to make the soil sticky and plasticity stronger and will be one day in advance of the mud mixed with water, wrapped with plastic cloth stand.

\section{Molding Skills}

The mud is one of the most common means of making potatoes in the Tibetan area. The most typical is the butterfly teapot. Mud is generally used at the bottom or part of the body. Tibetan soil pottery body is very thin, and some even thin as eggshell. Mud production is first in the palm of the kneading a mud, and then in the wooden pallets with palm or homemade wood to shoot the mud group shoot flat, shoot thin, and then use bamboo sticks or wood to draw the required size. Mold is divided into two kinds, one is the pottery on the mold, are wood carving, the other is the shape of the mold, but also divided into internal mold, external mold and symmetrical model three categories. The die-shaped mold is made of ceramic clay, and is generally divided into several models of different sizes. The inner mold is generally round bottom of the basin, the outer mold is flat basin. Repair blank is mainly the use of simple tools such as wood knife to remove the excess clay, or wood, wood scraping off the uneven surface and some decorative details. Polished, polished tools are yak skin, pebbles and so on. Tibetan artist dexterous fingers are also essential to repair blanks and grinding tools.

\section{Decorative Skills}

Stacking technology is in the body surface with a clay clay shape, similar to the high relief or round carving, mainly showing three-dimensional decorative effect. Ticking skills is to use bamboo, wood tools in the Earthenware Bang ticked a variety of patterns. Most of the soil pottery products are integrated tick ticking process. Porcelain is the tiles embedded in the body to form decorative patterns. When the body was semi-dry state, the need for the location of a variety of shapes inlaid tiles, tiles need to be simple in advance. Performance of mosaic skills of pottery products are mainly butter teapot, jug, brazier and so on. Printing techniques are divided into two kinds: one is the mold print, that is, when doing the pot in the mold on the inside there are patterns. Dege County incense plate surface pattern, jar outside the paste pattern and teapot pot pattern are stamped on the pattern. The other is the pattern of paper, made of pottery, with a pattern of wooden or ceramic rattan to form the surface of the dishes. The pattern is common in the wooden pots of Muli County. In addition, there are embossed, hollow, apply, additional skills are also commonly used in Tibetan soil pottery production. Sichuan Tibetan soil pottery burning methods are mostly flat to burn, individual places using pit-type kiln. The address of the kiln is usually open up a piece of open space not far from the workshop, some open air, and some take a simple shed, fuel piled in the shed. There are some areas will be based on the need to temporarily find the place where the kiln. Some areas will be burned in the last to cover a thick layer of wheat straw or straw, called "glaze." Sichuan Tibetan pottery, both from the craft or pottery on the decorative shape, there are many can withstand the study and study of the connotation, although seemingly rough, but has a very significant national characteristics and geographical characteristics. With the emergence of mechanized lines and other production methods, the traditional handicrafts, folk spontaneously formed a variety of traditional crafts how to be inherited, the government should be how to coordinate the relationship between the industry and its norms, ceramic artists should be how to characterize their work, How to position their own identity, these thinking related to the traditional crafts of the ecological environment, whether the traditional handicrafts can be a virtuous circle and long-term development. 


\section{The Influencing Factors of the Development of Earthenware}

Tate's decorative patterns are also affected by the natural environment. In the Tibetan pottery pottery in addition to the decorative patterns of Tibetan Buddhism and the color of the fish pattern, the geometric pattern to use the most, little plant pattern. This should be related to the natural geographical environment of Diqing. Alpine mountainous areas, and more growth of cold-tolerant trees, rarely survive fragile and delicate flowers, living in such an environment, the Tibetan natural and flowers tender grass things not much contact, and even make soil pottery decorative patterns to a variety of patterns of geometry Pattern of the main situation. The impact of living customs on the location of artifacts is great. Tibetan people sitting on the bench is generally low, they even prefer to sit cross-legged, often use the butter tea and other food utensils are placed directly on the ground, so it affects the soil pottery decorative parts. Almost all of the carefully crafted patterns are placed in the lid of the artifacts and more than half the position of the drums, which is the range of the user's eyes, and the parts below the belly twist are simply decorated, deal with. In the Tibetan areas of Yunnan, the elderly agreed to live with the eldest son, if the family has no son, by the long son-in-law to take the burden of this responsibility. So many generations living together, eat together, is bound to ask the soil pottery can not be too small, so the use of high frequency of the pot pot are high in the $20 \mathrm{~cm}$ up and down, the depth of about $15 \mathrm{~cm}$, abdominal diameter is often more than $20 \mathrm{~cm}$, even small Some of the casserole can also burn a five or six people a one-time meal. It can be seen that Earthenware is designed for the Tibetan people's life. But also because the parents should be with the eldest son, resulting in the eldest son of the family can not stay away from their homeland. The author in the soup heap when he had encountered such an example: a Tibetan young man very dance talent, in the joy of Shambhala Dance Conference was the famous dancer Yang Liping selected to join her guidance planning "Yunnan Impression "of the creative team, and to all over the country touring. Outside the days of his vision, but also made him have long been engaged in the ideal of dance art, but he can not violate the Tibetan customs and traditional values, after four years of so-called "wandering", he decided Decided to return to the origin, to assume the responsibility of the family, began to learn Earthenware technology, he is not very much in love with the pottery industry. We should be sorry for this young man who has a lofty ideals and can not achieve it. We should also see the other side of this special practice. It has made the Tibetan soil and Earthenware successfully completed the inheritance of the father and the mother. Extended way, and in a group or love or helpless young people continue to spread down.

Yunnan Tibetan area is a paradise of Tibetan Buddhism, where Tibetans are almost all religious. And every morning they shall be holy at the shrines of the church, and shall be blessed with rosin, and the incense burners of the lofts shall be burned to the heaven and earth, and every one of them shall be sent to the man Mani piled to the mountain gods. Tibetan people of this devout faith directly reflected in the pottery of the type and decoration. With the improvement of the educational level of the local potters, they are also deeply aware of the importance of carrying forward the Tibetan culture and the Tibetan Buddhist culture in keeping with the characteristics of the soil and Earthenwareism. Therefore, in addition to inheriting the circulation and decoration, but also carefully study the Tibetan books, hoping to bring more Tibetan cultural color and Tibetan Buddhist symbols of the contents of the earthenware to the creation of them.

\section{Conclusion}

Tibetan Earthenware through the history and nature of the double carving, material and spiritual dual choice, continue to accumulate as a unique Tibetan folk pottery crafts heritage, known as the "original pottery culture of living fossils." Tibetan soil pottery is the Tibetan people in their own specific natural environment and social and cultural environment continue to understand their own production and living needs continue to meet the results. From the creation and development of Tibetan pottery art form, the emotional expression of decorative patterns, the logical concept of operation process to the understanding of the environment to the market, the introduction and use of 
technology, etc., all reflect the Yunnan Kangba Tibetan people continue to self The discovery and transformation. Therefore, the artistic characteristics of the Tibetan soil and pottery are the result of the co-creation by the producers and the users, and the crystallization of the Tibetan people from generation to generation.

\section{References}

[1] Zhang Ganlin. Pottery Drum Casting - Yunnan Nixi Earthenware's craft protection, heritage and revitalization [J]. Agricultural archeology, 2011 (01)

[2] Wang Xin, Yu Shaoqi. Analysis of the artistic characteristics of Nishi Tuo Earthenware [J]. Foshan Ceramics, 2011 (01)

[3] Zhang Gan Lin. Yunnan Shangri-La Rise Tibetan pottery [J]. Literary Contention, 2010 (24)

[4] Chen Yan. Analysis of the history of the Naxi and Yunnan Tibetan political relations [J]. Journal of Yunnan Agricultural University, 2010 (03)

[5] Kang •Gesang Yi Xi. Tibetan Karma Kagali school of Tangka to the Han Dynasty green landscape techniques to absorb [J]. Journal of Tibet University, 2010 (01)

[6] Ning Danhua, Lei Yongming. Nixi Heiearthenware decorative techniques [J]. Ceramic Science and Art, 2009 (02) 